\title{
Study on Evaluating Innovation Ability of High-tech Industry Based on Particle Swarm Synthesis Optimization
}

\author{
Jingyu YIN*, Yi SU
}

\begin{abstract}
The innovation capability of high-tech industry reflects international competitiveness of a country. In order to scientifically evaluate the innovation capability, this paper proffers the comprehensive evaluation of the particle swarm synthesis optimization based on deviation maximization, principal component analysis and TOPSIS method. The evaluation index system of the innovation capability of high-tech industry is constructed; the paper conducts the empirical research through the particle swarm synthesis algorithm combined with provincial yearbook data on 30 provinces in China, and obtains the technological innovation capability results and rankings of each province's high-tech industry. The empirical results also show that the overall innovation capability of China's high-tech industry shows the growth trend, indicating that the implementation of an innovation-driven development strategy and other related policies have achieved suitable results. At the same time, the level of development in the eastern part of China is always higher than that of the central region and the western region. The paper further analyses reasons of differences in the development level of different regions. The particle swarm synthesis optimization has strong applicability in a comprehensive evaluation. This paper provides an effective reference for evaluating the innovation ability of the high-tech industry.
\end{abstract}

Keywords: combination evaluation; empirical analysis; high-tech industry; innovation capability; particle swarm synthesis optimization

\section{INTRODUCTION}

With the globalization of the development of the knowledge economy, the high technology industry has become the key to cultivate national core competitiveness. The high-tech industry needs intensive and concentrated R\&D investment; it is an industry group of manufacturing, marketing and service through advanced science and technologies. The industry's distinguishing feature is the combination of knowledge-intensive and technologyintensive pursuits. In the high-tech industry development process, the industrial innovation capability is particularly important. This capability represents the basic ability of innovation elements to aggregate, integrate and promote continuous innovation in a certain industrial area. The innovation ability of the high-tech industry represents the competitive level of a country in the international market; this is an important means by which to enhance its regional competitiveness.

Analysing the development level of the high-tech industry's innovation ability has important effect on improving the overall innovation capability of the hightech industry in China. The innovation ability of the hightech industry can to a certain extent represent the development level of the high-tech industry and exert a more important influence on economic development. To objectively assess the development level of the high technology industry is beneficial to formulate the national science and technology development strategy. Scholars have used different research methods and construct different index systems to evaluate the innovation capability of high-tech industries. But most studies only use a single method to evaluate the innovation ability of the high-tech industry. To compensate for the limitations of the single evaluation method, through building evaluation index system of high-tech industry innovation ability, this paper uses the maximum deviation, principal component analysis and Topsis method to evaluate the innovation capability of the high-tech industry respectively; further, the paper uses the particle swarm synthesis algorithm to realize the comprehensive evaluation of the three single methods and assesses high-tech industry innovation ability by using the combination evaluation method.

From the regional perspective, this paper summarizes the characteristics of the provincial high-tech industry innovation capability and constructs a model for evaluating the high-tech industry innovation capability from four perspectives: input of innovation resources, innovation implementation of capacity input, innovation output indicators and innovation environment support. Based on the former single method, the particle swarm synthesis optimization is applied to combine three methods. This paper calculates the innovation ability value of high-tech industries in each province by the particle swarm synthesis optimization and analyses the innovation ability of the high-tech industry in China from three perspectives of east, west and central China.

\section{LITERATURE REVIEW}

Scholars analyzed the development of innovation capability by distinguishing method; in addition, certain scholars studied the industrial innovation level from different research perspectives. The evaluation of innovation capability has become a popular topic of research. In [1] Raghuvanshi et al. found that the innovation capability in micro-enterprises were formed by the resources, networking, risk taking and involvement. In order to enhance the understanding of the essence of product innovation capability, in [2] Sharma et al. assessed the conceptualization and construct validity of product innovation capability systematically. In [3] Saunila took the small and medium sized enterprises as the research object, and presented the framework for improving innovation capability through performance measurement. Based on matter-element and extension set theory, the authors in [4] established the multidimensional extension and matter element model and evaluated the innovation ability through the largest correlation degree criteria. In order to measure innovation capability in exporting firms, in [5] Vicente et al. identified the innovscale as the important dimension. By using IVIFMSM operator, in [6] 
a novel algorithm is developed to evaluate the innovation capability of high technology enterprises and an example to estimate is provided. The utility function is built by considering experts preference, in [7]. Yang et al. further employed the modified TOPSIS method to overall evaluate the innovation abilities and rank the innovative enterprises.

In [8] $\mathrm{Lu}$ et al. built a system for evaluating the innovation capability through the factor analysis method. In [9] Hong et al. evaluated and analyzed the innovation ability of each high-tech industry using the fuzzy Borda method. Based on the R\&D personnel input and R\&D funding input, in [10] Zhao et al. focused on the important role of knowledge stock and used the stochastic frontier approach to evaluate the innovation capability of the hightech industry during the transformation period. In [11] $\mathrm{Li}$ et al. extracted key factors by using the Delphi method and the fuzzy comprehensive evaluation method. In [12] Jiang et al. used data envelopment analysis to calculate the innovation efficiency of high-tech industries in 31 provinces. In [13] Qazi et al. conducted an empirical study on the high-tech industry using the Malmquist index method from the two aspects of the efficiency of selfdirected research and development and the efficiency of technology transfer. In [14] $\mathrm{Li}$ et al. integrated the uncertain information into the overall substitution value using an UEWGA operator. In [15-17] the authors also used improved Topsis method and the DEA-bootstrap method to analyze the industrial innovation ability.

Scholars have proffered different means to improve the innovation ability of the high-tech industry and deepen the research level. Broad space for development remains in the evaluation of innovation capability for high-tech industries. At the same time, many studies only use a single method to evaluate the innovation ability of the high-tech industry. Each method has its own advantages and disadvantages; however, because of its own characteristics, there are certain inevitable limitations. In fact, using a single method leads to a one-sided problem during the evaluation process because of its operation mechanism. Although the subjective evaluation method is easily influenced by subjective effects, it can also utilize expert experience. Partial evaluation method can avoid subjective factors based on objective weight but is also vulnerable to be affected by random error. The main limitation of three single evaluation methods in this paper include that, according to the change in the sample set and index characteristics, the maximum deviation can reflect the importance of each index objectively. However, it may neglect the empirical factors of experts. Although the principal component analysis method can flexibly apply objective data, there is a lack of the analysis results that have great dependence on the structure of the original variables [18], and the inconsistency of the sign may lead to a phenomenon in which the relatively weak indicator plays an important role in the decision-making [19]. Because of the complexity of solving the decision matrix, the calculation of positive and negative ideal solutions is more difficult. And the Topsis method is greatly influenced by subjective factors. The comprehensive evaluation method can be applied to combine the advantages of each method in $[20,21]$ to a certain extent, to more comprehensively reflect the true levels of the evaluated objects. The evaluation of high-tech industry innovation ability is regarded as a multi-attribute decision-making problem. The particle swarm synthesis optimization has strong applicability to evaluate the innovation ability with its advantages of simple calculation, fewer parameters and faster search speed in [22]. The synthesis algorithm in this paper is based on three single methods, and they are combined by particle swarm synthesis optimization to compensate for the shortcomings of each single method and to avoid the mutual interference of statistical data.

\section{CONSRUCTION OF INDEX SYSTEM}

Industrial development can provide a necessary guarantee for high-tech industry to enhance its innovation ability. Furthermore, the innovation ability of the high-tech industry can improve the industrial competitiveness of the high-tech industry. Therefore, it is of great significance to evaluate the innovation ability of the high-tech industry [23]. This paper agrees that the innovation capability of the high-tech industry is that the high-tech industry effectively combines and integrates internal and external resources. This capability allows the high-tech industry to transform cutting-edge knowledge, ideas and technologies into new products and new processes by using various innovative means. It is also the ability to continuously improve the competitiveness of the high-tech industry.

The innovation ability of the high-tech industry is affected by multiple factors. Therefore, it is difficult to be directly measured. It is necessary to select appropriate alternative indicators to indirectly characterize the technological innovation capability of high-tech industries in each province. Based on previous research in $[8,9,10$, $11,15]$, according to the principle of scientific quality and operability, combined with the actual development of hightech industry technological innovation activities in China's provinces, municipalities and autonomous regions, considering the availability and reliability of data the paper utilizes the following four aspects: input of innovation resources, capability of innovation implementation input, innovation output and capability of innovation environment support; it also establishes an index system of high-tech industry innovation ability evaluation, as shown in Tab. 1 .

Table 1 Evaluation index system

Expenditure for new product development (Million yuan) $x_{11}$

R\&D personnel equivalent to full-time equivalent (Person) $x_{12}$

Average number of employees in high-tech industry (Person) $x_{13}$ Number of R \& D institutions (Unit) $x_{21}$

Cost of instruments and equipment (Billion yuan) $x_{22}$ Sales revenue of new products (Billion yuan) $x_{23}$ Total profit (Billion yuan) $x_{24}$

Number of patent applications (Piece) $x_{31}$

Number of effective inventions (Piece) $x_{32}$

Government funds (Million yuan) $x_{33}$ Enterprise funds (Million yuan) $x_{41}$ Enterprise number (Unit) $x_{42}$

Project completion rate (\%) $x_{43}$

\section{RESEARCHMETHOD}

Different indicators have different dimensions and magnitudes. Therefore, this paper adopts the extreme value standardization method by Eq. (1) to process the raw data. This method will not only reduce the degree of 
underestimation of each index in the degree of discretization, but also avoids the influence of dimension among the indicators:

$$
x_{i j}(t)=\frac{v_{i j}(t)-\min v_{i j}(t)}{\max v_{i j}(t)-\min v_{i j}(t)}
$$

Acoording to sample values $x_{i j}$ and indicator weight $w_{i}$, for the method of maximizing deviations, total deviation of the number $i$ goal from the other goals is calculated. In [24] Chen et al. calculate total deviation of all evaluation objects from other evaluation objects by:

$$
\begin{aligned}
& D_{i j}=\sum_{j=1}^{n}\left|x_{i j} w_{j}-x_{i k} w_{j}\right| k=1,2, \ldots, m \\
& D_{j}=\sum_{i=1}^{m} D_{i j}=\sum_{i=1}^{m} \sum_{k=1}^{m} w_{j}\left|x_{i j}-x_{i k}\right|
\end{aligned}
$$

The appropriate weight vector should satisfy that the total deviation for all attributes of all schemes can achieve the maximum extent. The regulation linear programming model is built and solved by using the Lagrange multiplier function:

$$
\begin{aligned}
& \max _{j}=\sum_{i=1}^{m} \sum_{k=1}^{m} \sum_{j=1}^{n} w_{j}\left|x_{i j}-x_{i k}\right| \\
& \text { s.t. } \sum_{j=1}^{n} w_{j^{2}}=1, w_{j}>0 \\
& L(w, \lambda)=\sum_{i=1}^{m} \sum_{k=1}^{m} \sum_{j=1}^{n} w_{j}\left|x_{i j}-x_{i k}\right|+\lambda\left(\sum_{j=1}^{n} w_{j}{ }^{2}-1\right)
\end{aligned}
$$

The unitized weight vector is finally obtained. Since the traditional weighting vectors usually satisfy the normalized constraints, not the unitized constraints, the final evaluation weight is obtained after the normalization process. The evaluation results in various provinces are obtained by multiplying the evaluation weight by each index and ranking them according to the size of the evaluation results.

$$
w_{i}^{*}=\frac{\sum_{i=1}^{m} \sum_{k=1}^{m} w_{j}\left|x_{i j}-x_{i k}\right|}{\sum_{i=1}^{m} \sum_{k=1}^{m} \sum_{j=1}^{n}\left|x_{i j}-x_{i k}\right|}
$$

For the Principal component analysis, in [25] Abson et al. think that if the $K M O$ value is greater than 0.6 , it is suitable for further tests of the principal component analysis. Because characteristic root is greater than 1 , the cumulative variance contribution rate of the former $r$ principal components is more than $85 \%$ principles, and the number of principal components is determined and evaluated based on $r$ principal components. Using the initial factor loads $f_{i j}$ and characteristic roots $\lambda$, the decision coefficient matrix $u_{i j}$ is obtained:

$$
\mathrm{u}_{i j}=\frac{f_{i j}}{\sqrt{\lambda}_{j}}, j=1,2, \ldots, m
$$

Then, construct the comprehensive evaluation function to obtain the linear combination equation of each principal component. According to each indicator coefficient and the corresponding variance contribution rate of each principal component can be obtained the weight of each index and calculated the technical innovation capability of the hightech industry in each province.

According to the Topsis method, the weights corresponding to each index are multiplied by the normalized matrix to build weighted decision matrix $M=$ $\left(X_{i j}\right)_{m \times n}$ in [26]. The positive ideal solution and the negative ideal solution are determined based on the matrix:

$$
\begin{aligned}
& \boldsymbol{A}^{+}=\left\{\max x_{i j}\right\}=\left\{x_{1}^{+}, x_{2}^{+}, \ldots, x_{n}^{+}\right\} \\
& \boldsymbol{A}^{-}=\left\{\min x_{i j}\right\}=\left\{x_{1}^{-}, x_{2}^{-}, \ldots, x_{n}^{-}\right\}
\end{aligned}
$$

Then calculate the degree of separation of each provincial innovation ability and the positive ideal solution, and the degree of separation of each provincial innovation ability and the negative ideal solution:

$$
\begin{aligned}
& d_{i}^{+}=\sqrt{\sum_{j=1}^{n}\left(x_{i j}-x_{j}^{+}\right)^{2}} \\
& d_{i}^{-}=\sqrt{\sum_{j=1}^{n}\left(x_{i j}-x_{j}^{-}\right)^{2}}
\end{aligned}
$$

Based on the degree of separation, the technical innovation capability of the high-tech industry is determined by the $Q_{i}$ value:

$Q_{i}=d_{i}^{-} /\left(d_{i}^{+}+d_{i}^{-}\right)$

This paper treats the provincial innovation capacity by three methods respectivly as the basic particles: set the initial value of the particle in the population and evaluate the population, calculate the fitness function of each particle:

fitness $=\sum_{i=1}^{d} \frac{A_{(i)}+B_{(i)}+C_{(i)}}{3}$

$A_{(i)}$ et al. represent the value of innovation ability by applying the former three methods respectivly. The fitness function is used to evaluate the initial fitness of individual populations. The individual historical optimal $p_{\text {best }}$ and the global historical optimal $g_{\text {best }}$ are established accordingly. In [27] Schutte et al. compare the particle fitness function value fitness and population history of optimal $p_{\text {best }}$. During each iteration process, the velocity and position of the 
particle are updated by the individual extrema and the population extrema in [28]:

$$
\begin{aligned}
& V_{i d}(t+1)=w V_{i d}(t)+c_{1} r_{1}\left(P_{i d}(t)-X_{i d}(t)\right)+c_{2} r_{2}\left(P_{g d}(t)-X_{i d}(t)\right) \\
& X_{i d}(t+1)=X_{i d}(t)+V_{i d}(t+1)
\end{aligned}
$$

Circulate the process constantly until the maximum number of iterations is satisfied, thus realize the search for the optimal solution in the solution space, and get the provincial innovation ability of high-tech industry [29]. According to the empirical value obtained through repeated experiments, this paper selects the best parameters of each algorithm to calculate. Learning factor $c_{1}=c_{2}=2$, the population size is set to $30, T_{\max }$ is 200 for the maximum evolutionary algebra [30]. $w$ adopts dynamic inertia weight and applies a linearly decreasing weight strategy for equation shown as follows $w_{\min }=0.4, w_{\max }=$ 0.9 :

$$
w=w_{\max }-\frac{\left(w_{\max }-w_{\min }\right) \times t}{T_{\max }}
$$

\section{EMPIRICAL ANALYSIS}

To scientifically evaluate the innovation capability of high-tech industries of each province, this paper uses the high-tech industries of 30 provinces, municipalities and autonomous regions in China as the basic unit. According to the reality, this paper selects the relevant data from 2009 to 2015 for the empirical research. The sample data originate from technical statistics yearbook on high technology industry from 2010 to 2016. The National Bureau of Statistics finds that the high technology industries include the pharmaceutical, aviation, spacecraft and equipment, communications equipment, computer and office equipment, medical equipment and instruments, information chemicals and et al. After the original data are standardized by extreme values, the index values of all the years are greater than 0.7 . This index indicates that all the experimental samples are suitable for principal component analysis. This paper calculates the innovation ability of the high-tech industry of each province in China according to the three single evaluation method steps proposed in the previous section. Due to space limitations, this paper just provides the assessment results of 2015 , as shown in Tab. 2. The evaluation results obtained by the three single evaluation methods are not consistent with rankings results.

Furthermore, particle swarm synthesis optimization method is applied to realize the combination of three methods. As a comprehensive evaluation method, we also evaluate the high-tech industry innovation capacity of 30

\begin{tabular}{|c|c|c|c|c|}
\hline & Maximizing deviation & Principal component analysis & Topsis method & Particle swarm optimization algorithm \\
\hline Beijing & 0.1992 & 0.1404 & 0.1778 & 0.1673 \\
\hline Tianjin & 0.1969 & 0.1079 & 0.1403 & 0.1426 \\
\hline Hebei & 0.1446 & 0.0779 & 0.0814 & 0.0931 \\
\hline Shanxi & 0.0943 & 0.0348 & 0.0547 & 0.0539 \\
\hline Neimenggu & 0.1096 & 0.0349 & 0.0681 & 0.0652 \\
\hline Liaoning & 0.2037 & 0.0826 & 0.1179 & 0.1287 \\
\hline Jilin & 0.1254 & 0.0532 & 0.0726 & 0.0761 \\
\hline Heilongjiang & 0.1305 & 0.0490 & 0.0724 & 0.0765 \\
\hline Shanghai & 0.2109 & 0.1422 & 0.1761 & 0.1699 \\
\hline Jiangsu & 0.5993 & 0.5978 & 0.5402 & 0.5724 \\
\hline Zhejiang & 0.2977 & 0.2626 & 0.2530 & 0.2629 \\
\hline Anhui & 0.1877 & 0.1265 & 0.1234 & 0.1394 \\
\hline Fujian & 0.1595 & 0.1157 & 0.1082 & 0.1202 \\
\hline Shanxi & 0.1343 & 0.0807 & 0.0797 & 0.0899 \\
\hline Shandong & 0.3120 & 0.2621 & 0.2476 & 0.2680 \\
\hline Henan & 0.1806 & 0.1323 & 0.1298 & 0.1419 \\
\hline Hubei & 0.1782 & 0.1239 & 0.1223 & 0.1359 \\
\hline Hunan & 0.1867 & 0.1124 & 0.1108 & 0.1281 \\
\hline Guangdong & 0.8786 & 0.9247 & 0.8736 & 0.8852 \\
\hline Guangxi & 0.1121 & 0.0471 & 0.0643 & 0.0683 \\
\hline Hainan & 0.0532 & 0.0183 & 0.0254 & 0.0270 \\
\hline Chongqing & 0.1380 & 0.0797 & 0.0802 & 0.0932 \\
\hline Sichuan & 0.2137 & 0.1205 & 0.1379 & 0.1508 \\
\hline Guizhou & 0.0956 & 0.0386 & 0.0493 & 0.0544 \\
\hline Yunnan & 0.0810 & 0.0302 & 0.0434 & 0.0447 \\
\hline Shanxi & 0.2475 & 0.0946 & 0.1902 & 0.1722 \\
\hline Gansu & 0.0948 & 0.0305 & 0.0567 & 0.0530 \\
\hline Qinghai & 0.0571 & 0.0165 & 0.0311 & 0.0279 \\
\hline Ningxia & 0.0957 & 0.0284 & 0.0595 & 0.0554 \\
\hline Xinjiang & 0.0664 & 0.0200 & 0.0375 & 0.0342 \\
\hline
\end{tabular}
provinces.

Table 2 Evaluation results of the innovation ability by each single method

The results obtained by the fourth method are also shown in Tab. 2 and they are also different from those of former three results. Spearman's rank correlation coefficient is applied to compare three single methods and the comprehensive evaluation method. The rank correlation coefficient results among the particle swarm synthesis optimization and the other three methods change from 0.996 to 0.999 respectively. The results are better than other pairwise comparison. Through the calculation, the method of particle swarm synthesis optimization is more 
consistent than the other three single evaluation methods. The results show that compared with the single evaluation method, particle swarm synthesis optimization is more scientific in obtaining the conclusions of the research. It cannot only enhance the evaluation conclusion of high consistency but also weaken the evaluation conclusion of low heterogeneity. Each province's technological innovation capability is also calculated by the method of particle swarm synthesis optimization from 2009 to 2015. Due to space limitations, this paper only provides the assessment results from 2013 to 2015, as shown in Tab. 3 . Based on the provincial result and the division of the eastern, central and western regions of China, the innovation capability of high-tech industry of the national average level and every region is calculated and shown in Fig. 1 respectively.

Table 3 The comprehensive evaluation results of the innovation ability of the high-tech industry

\begin{tabular}{|c|c|c|c|c|c|c|}
\hline & 2013 & Ranking & 2014 & Ranking & 2015 & Ranking \\
\hline Beijing & 0.1534 & 5 & 0.1545 & 7 & 0.1673 & 7 \\
\hline Tianjin & 0.1126 & 14 & 0.1130 & 15 & 0.1426 & 9 \\
\hline Hebei & 0.0850 & 17 & 0.0846 & 17 & 0.0931 & 17 \\
\hline Shanxi & 0.0519 & 23 & 0.0484 & 24 & 0.0539 & 25 \\
\hline Neimenggu & 0.0622 & 21 & 0.0537 & 23 & 0.0652 & 22 \\
\hline Liaoning & 0.1355 & 8 & 0.1295 & 9 & 0.1287 & 13 \\
\hline Jilin & 0.0805 & 18 & 0.0806 & 18 & 0.0761 & 20 \\
\hline Heilongjiang & 0.0709 & 20 & 0.0717 & 20 & 0.0765 & 19 \\
\hline Shanghai & 0.1469 & 7 & 0.1914 & 5 & 0.1699 & 6 \\
\hline Jiangsu & 0.5502 & 2 & 0.5737 & 2 & 0.5724 & 2 \\
\hline Zhejiang & 0.2277 & 4 & 0.2431 & 3 & 0.2629 & 4 \\
\hline Anhui & 0.1066 & 15 & 0.1178 & 14 & 0.1394 & 11 \\
\hline Fujian & 0.1156 & 13 & 0.1235 & 10 & 0.1202 & 15 \\
\hline Shanxi & 0.0892 & 16 & 0.0995 & 16 & 0.0899 & 18 \\
\hline Shandong & 0.2328 & 3 & 0.2425 & 4 & 0.2680 & 3 \\
\hline Henan & 0.1161 & 12 & 0.1232 & 11 & 0.1419 & 10 \\
\hline Hubei & 0.1233 & 10 & 0.1211 & 13 & 0.1359 & 12 \\
\hline Hunan & 0.1186 & 11 & 0.1223 & 12 & 0.1281 & 14 \\
\hline Guangdong & 0.7798 & 1 & 0.8177 & 1 & 0.8852 & 1 \\
\hline Guangxi & 0.0720 & 19 & 0.0703 & 21 & 0.0683 & 21 \\
\hline Hainan & 0.0258 & 30 & 0.0303 & 29 & 0.0270 & 30 \\
\hline Chongqing & 0.0599 & 22 & 0.0802 & 19 & 0.0932 & 16 \\
\hline Sichuan & 0.1351 & 9 & 0.1396 & 8 & 0.1508 & 8 \\
\hline Guizhou & 0.0366 & 28 & 0.0429 & 26 & 0.0544 & 24 \\
\hline Yunnan & 0.0504 & 24 & 0.0415 & 27 & 0.0447 & 27 \\
\hline Shanxi & 0.1491 & 6 & 0.1567 & 6 & 0.1722 & 5 \\
\hline Gansu & 0.0465 & 25 & 0.0548 & 22 & 0.0530 & 26 \\
\hline Qinghai & 0.0375 & 27 & 0.0214 & 30 & 0.0279 & 29 \\
\hline Ningxia & 0.0416 & 26 & 0.0447 & 25 & 0.0554 & 23 \\
\hline Xinjiang & 0.0319 & 29 & 0.0339 & 28 & 0.0342 & 28 \\
\hline
\end{tabular}

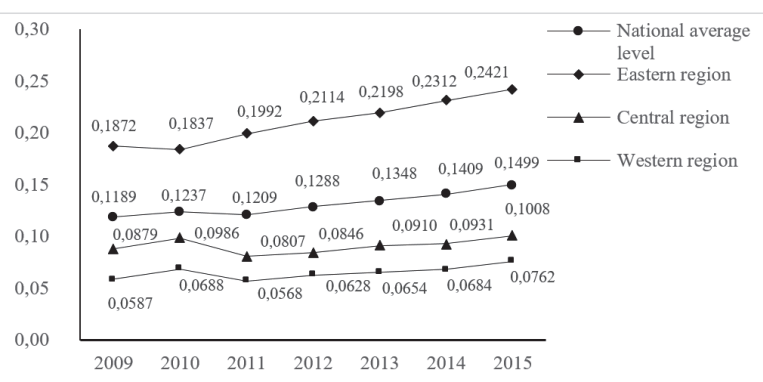

Figure 1 Results among different regions

From 2009 to 2015, the overall innovation capability of China's high-tech industry showed a growth trend, indicating that the implementation of an innovation-driven development strategy and other related policies has achieved suitable results, and the innovation capability of high-tech industries in all provinces has been generally increased. The level of development in the eastern part of China is always higher than that of the central region and the western region. Compared with the national average level, the innovation capability of high-tech industries in the eastern region is always above the national average every year, while the central and western regions are always below the national average level. In terms of time, the innovation capability of high-tech industries in the eastern region decreased slightly from 2009 to 2010; it declined from 0.1872 to 0.1837 . However, the capability increased steadily year over year during the period of 2010 to 2015 , with a significant increase from 0.1837 to 0.2421 . Although the eastern region maintained a high level of steady development in most of the provinces in the past seven years, there are internal differences because of bipolar development. Guangdong, Zhejiang, Jiangsu, Shandong, Beijing, Shanghai and Liaoning are ranked at the forefront of China's high-tech industry innovation capability. The rankings are generally in the top seven. Specifically, Guangdong Province has been ranked first for seven years, and its high-tech industry innovation capacity increased from 0.6482 in 2009 to 0.8852 in 2015 . Hebei Province's high ranking in the innovation ability of hightech industries is relatively stable and is always in the middle of the provinces at 17 th. Although the high-tech industries in Guangxi and Hainan are less volatile, they are always in the rankings at 20 and 30, respectively, ranking behind the remaining cities in the eastern region. In 2009, Hainan Province, which had the lowest innovation abilities in high-tech industries, posted a slight increase in ranking for the first time in seven years. Hainan Province continued to rank last in the 2015 comparison; the innovation 
capability of its high-tech industries only increased by 0.0057 .

Both the central region and the western region achieved slight growth in 2009 and 2010, increasing from 0.0879 to 0.0986 and from 0.0587 to 0.0688 , respectively. However, the regions are slightly decreasing from 0.0986 to 0.0807 from 2010 to 2011 , then from 0.0688 to 0.0568 . Conversely, there was a growth trend from 2011 to 2015 , and the upward trend did not obviously increase to a lesser extent, only from 0.0807 to 0.1008 and from 0.0568 to 0.0762 for the regions, respectively. The increase is only 0.0201 and 0.0194 . Henan and Hubei in the central region are more stable in the ranking between No. 10 and 13, indicating that high-tech industries also have a higher level of technological innovation. Inner Mongolia, Jilin, and Heilongjiang provinces have made great changes in the ranking of their high-tech industry innovation, with a sharp decline, which has exceeded 5 ranks. Jiangxi Province experienced a large jump in 2010 and 2011 but decreased again over the next few years, to $18^{\text {th }}$ in 2015 . Anhui and Hunan ranked first in the process, although their rankings changed occasionally. However, the regions were in an overall uptrend. Anhui and Hunan gained more than eight positions in the upper rankings through the year-on-year improvement. In Shanxi, the regions also increased to 25 and entered the middle ranks. While the overall western region is at a lower level, only Sichuan Province has performed well. This province has always been in the upper ranks of the innovation capability of high-tech industries. Chongqing has also made continuous efforts to enter the middle rank in 2015. Furthermore, the rankings of Guizhou, Yunnan, Shanxi, Gansu, Qinghai, Ningxia and Xinjiang Province, although occasionally changed, remain in the downstream area where the technological innovation capability of high-tech industries in China is relatively low.

The analysis of the reasons for the empirical results shows that the eastern region has a wealth of innovative resources, and the market development in the eastern portion is relatively perfect; the local innovation infrastructure is more complete. Many high-tech enterprises in the eastern region have independent research and development institutions, which provide an important foundation for their systematic and orderly innovation. At the same time, the eastern region generally has first-rate institutions in the form of universities and scientific research institutes, which also provide strong guarantees for the innovation and development of high-tech industries. The eastern region has introduced a large amount of highquality external funds because of the advantage of geographical location. The government has created a strong atmosphere for innovation and innovative policies. The government also has led enterprises and personnel to the eastern region to push forward their high-tech innovation capability.

Conversely, the development of high-tech industries in the central region started relatively late, and many indicators were close to 0 in the earlier years. However, under the influence of the national innovation-driven development strategy, the pace of development of hightech industries is gradually accelerating. At the same time, as the cost of human capital is increasing year by year, the central region has successfully transferred part of the eastern region's high-tech industries to it. This region also vigorously developed high-tech industries combined with its low-cost labor advantage. However, due to the weak foundation and more innovative talents being transferred to the east, the development level of the high-tech industries only maintained slow growth. The economic development in the western region is relatively low. Although the region has a vast area, it is limited by the heavy shortage of human capital. The limited level of development of infrastructure such as local universities and colleges results in a shortage of innovative talents and a very weak foundation for the innovation and development of high-tech industries. At the same time, because its geographical location is inland, external investment is very difficult to access. The lack of competition in the market has led to a single economic structure in the western region and a very insufficient driving force for the development of the high-tech industries.

\section{CONCLUSION}

To solve inconsistent results for the single evaluation method, this paper proposes the particle swarm synthesis optimization based on the maximization of variance, principal component analysis and the Topsis method. The comprehensive evaluation method combines three single methods. Based on the data of 30 provinces in China, municipalities, and autonomous regions, this paper builds the research index system from the following four aspects: input of innovation resources, capability of innovation implementation input, innovation output and capability of innovation environment support. Additionally, this paper utilizes the single evaluation method to evaluate the innovation ability of high-tech industries separately, including the maximization of dispersion, the principal component analysis and the Topsis method. Furthermore, we use the method of particle swarm synthesis optimization to combine the three methods to evaluate and rank the innovation ability of 30 provincial high-tech industries. The main conclusions obtained are as follows: the particle swarm synthesis optimization, which combines the maximization of variance, principal component analysis and Topsis method, can achieve a more scientific evaluation of the innovation ability of the high-tech industry in China. Additionally, this method is verified by the empirical test. The particle swarm synthesis optimization method can better reflect the true level of the high-tech industry innovation ability compared to the other three single evaluation methods. At the same time, compared with the previous single method of evaluation, this comprehensive evaluation method can help verify each evaluation method. The particle swarm synthesis optimization can improve the scientific quality and accuracy of the evaluation of innovation capability.

The empirical results also show that the innovation capability of high-tech industries in all provinces has been generally increased, but there are large differences in the innovation capability of high-tech industries in various regions of China. Compared with the other two regions, the eastern region has the highest technological innovation capability of high-tech industries, however, two poles differences are within. The technological innovation capability of Hainan and Guangxi not only ranks very low in the eastern region, but also in the whole country. The 
level of development in the central region is normal, Inner Mongolia, Jilin, and Heilongjiang provinces have made great changes with a sharp decline in the ranking of their high-tech industry innovation, while the rest of provinces are stable in the ranking or in an overall uptrend. Only Sichuan province and Chongqing have performed well in the innovation capability, the level of the other provinces in the western region is still low in the innovation capability of the high-tech industry.

Based on the findings of the study, the following suggestions are made. Although the development of hitech industries in China's central and western regions began relatively later than in the eastern regions, the government has created many policies for manpower and materials in supporting high-tech industries. In the future, the government can further improve its support system and promote the development of high-tech industries in China's central and western regions. At the same time, due to the different resource endowments in different provinces, a large difference in the development basis exists. Indeed, different provinces need different levels of government support. In the future, more suitable resources and policies can be provided by the government to support the development needs of different provinces. The government needs to create an increasingly more appropriate innovation environment for high-tech industries in the regions to play a true guiding role. High-tech enterprises in the central and western regions, as the main body of high technology industry innovation, should actively construct independent R\&D institutions owned by enterprises. Hightech enterprises should attract a larger number of talented individuals with more innovative abilities and cultivate innovative talent through a more favorable treatment. At the same time, central and western regions should strengthen the construction of universities, R\&D institutions and research institutes, tilt the technological capabilities from the eastern region to the central and western regions, and encourage innovative talents to participate in the central and western regions through such measures as improving treatment. These enterprises can help universities and research institutes in the central and western regions improve their research and development levels to better cooperate with high-tech enterprises to achieve "organic integration of research". Using lessons from the successful experience of the eastern region and focusing on the introduction of advanced technologies, enterprises should encourage innovative talents to further explore existing technical fields and improve the technological capabilities of high-tech industries by improving their utilization of innovative capabilities. By fully utilizing the advantages of the "One Belt and One Road", the government will fully play to the advantages of local specialties in the central and western regions, share each other's advantages, resources and further enhance the innovation capability of high-tech industries through cooperation with neighboring countries.

The eastern region should continue to fully support the leading edge of the high technology industry's development while enriching the input of innovative resources and considering how to improve the utilization efficiency of innovative resources and help achieve higher quantity output with higher quality. The eastern region has amassed fruitful achievements in innovation in the high- tech industry; however, we need to focus more on the transformation of innovation results. Only new ideas and technologies can be applied to products, and the added value of products can maximize the profit. At the forefront of the national high-tech development, the high-tech enterprises in the eastern region should do the following: use world-class enterprises as the goal, continue to strengthen cooperation with excellent foreign enterprises, and continue to encourage the introduction of external funds. Using the advanced scientific research institutes and institutions of higher education research and development will enhance the existing innovation to further improve the innovation ability and strengthen the exploratory innovation ability. Targeting world-class technology leads to technological breakthroughs in new fields through the innovation of the core technology in the global competitive environment. We encourage eastern high-tech enterprises, universities and research institutions to implement extensive innovation cooperation with the midwest region. We also encourage these entities to fully utilize the existing advanced technology and the advantages of the central and western regions to create a new direction of innovation to further achieve coordinated and more efficient development of the high-tech industries in the eastern, central and western regions.

\section{Acknowledgements}

Funding: This research was supported by the National Natural Science Foundation of China (71403066, 71774036), the Social Science Foundation of Heilongjiang Province (17GLH21), the Natural Science Foundation of Heilongjiang Province (QC2018088), the Special Foundation of Central Universities Basic Research Fee (HEUCFW170907, HEUCFW180903, HEUCF180905).

\section{REFERENCES}

[1] Raghuvanshi, J., Agrawal, R., \& Ghosh, P. K. (2019). Measuring the innovation capability of micro enterprises in India. Benchmarking: An International Journal, 26(5), 14051430. https://doi.org/10.1108/BIJ-08-2018-0229

[2] Sharma, S. O. \& Martin, A. (2018). Re-thinking and reoperationalizing product innovation capability. European Business Review. European Business Review, 30(4), 374397. https://doi.org/10.1108/EBR-07-2016-0087

[3] Saunila, M. (2016). Performance measurement approach for innovation capability in SMEs. International Journal of Productivity and Performance Management, 65(2), 162-176. https://doi.org/10.1108/IJPPM-08-2014-0123

[4] Zhang, X. \& Yue, J. (2017). Measurement model and its application of enterprise innovation capability based on matter element extension theory. Procedia Engineering, 174, 275-280. https://doi.org/10.1016/j.proeng.2017.01.136

[5] Vicente, M., Abrantes, J. L., \& Teixeira, M. S. (2015). Measuring innovation capability in exporting firms: the INNOVSCALE. International Marketing Review, 32(1), 2951. https://doi.org/10.1108/IMR-09-2013-0208

[6] Sun, G. \& Xia, W. L. (2016). Evaluation method for innovation capability and efficiency of high technology enterprises with interval-valued intuitionistic fuzzy information. Journal of Intelligent \& Fuzzy Systems, 31(3), 1419-1425. https://doi.org/10.3233/IFS-162208

[7] Yang, C. H., Qiu, L. W., \& Ding, S. (2015). Evaluation method on innovation capability of the innovative 
enterprises based on experts' preference. Operations Research and Management Science, 1, 202-208.

[8] Lu, Y. D. \& Yu, F. (2010). The evaluation of the innovation capability of China's high-tech industries. International Business Research, 3(2), 87-91. https://doi.org/10.5539/ibr.v3n2p87

[9] Hong, Y., Niu, D. X., Xiao, B. W., \& Wu, L. N. (2015) Comprehensive evaluation of the technology innovation capability of China's high-tech industries based on fuzzy borda combination method. International Journal of Innovation Science, 7(3), 215-230. https://doi.org/10.1260/1757-2223.7.3.215

[10] Zhao, Z. Y. \& Yang, C. F. (2013). An empirical study on innovation capability of China's high-tech industry in transition period. China Soft Science, 1, 32-42.

[11] Li, T. \& Ding, Y. (2013). Technological capability evaluation model of marine high-tech industries in China based on borda and fuzzy comprehensive method. Journal of Convergence Information Technology, 8(1), 715-723. https://doi.org/10.4156/jcit.vol8.issue1.88

[12] Jiang, L., Jiang, Y., Wu, Z., Liao, D., \& Xu, R. (2016). The measurement of innovation efficiency of chinese high-tech industry using data envelopment analysis. Acta Oeconomica, 65(s2), 101-113. https://doi.org/10.1556/32.65.2015.S2.8

[13] Qazi, A. Q. \& Zhao, Y. (2013). Indigenous R\&D effectiveness, technology transfer and productivity growth: evidence from the hi-tech industry of China. International Journal of Computational Economics \& Econometrics, 3(1/2), 64-82. https://doi.org/10.1504/ijcee.2013.056269

[14] Li, J. \& Zheng, Z. (2012). Study on evaluation of technical innovation capacity of high-tech industry with uncertain linguistic information. Advances in Information Sciences \& Service Sciences, 4(4), 230-236. https://doi.org/10.4156/aiss.vol4.issue4.27

[15] Fan, D. C. \& Du, M. Y. (2017). Dynamic comprehensive evaluation of the high-tech industry technology innovation ability based on TOPSIS grey relation projection method-in the perspective of integration of Beijing-Tianjin-Hebei region. Operations Research \& Management Science, 26(7), 154-164.

[16] Cruz-Cázares, C., Bayona-Sáez, C., \& García-Marco, T. (2013). You can't manage right what you can't measure well: technological innovation efficiency. Research Policy, 42(67), 1239-1250. https://doi.org/10.1016/j.respol.2013.03.012

[17] Wang, Z. X. \& Wang, Y. Y. (2014). Evaluation of the provincial competitiveness of the Chinese high-tech industry using an improved topsis method. Expert Systems with Applications, 41(6), 2824-2831. https://doi.org/10.1016/j.eswa.2013.10.015

[18] Karamizadeh, S., Abdullah, S. M., Manaf, A. A., Zamani, M. \& Hooman, A. (2013). An overview of principal component analysis. Journal of Signal \& Information Processing, 4(3B), 173-175. https://doi.org/10.4236/jsip.2013.43B031

[19] Ueda, T. \& Hoshiai, Y. (2017). Application of principal component analysis for parsimonious summarization of dea inputs and/or outputs. Journal of the Operations Research Society of Japan, 40(4), 466-478 https://doi.org/10.15807/jorsj.40.466

[20] Wallenius, J., Dyer, J. S., Fishburn, P. C., Steuer, R. E., Zionts, S., \& Deb, K. (2008). Multiple criteria decision making, multiattribute utility theory: recent accomplishments and what lies ahead. Management Science, 54(7), 1336-1349. https://doi.org/10.1287/mnsc.1070.0838

[21] Zhang, F. \& Liu, Z. (2017). Combined evaluation methods: a literature review. Journal of Systems Engineering, 32(4), 557-569.

[22] Kennedy, J. \& Eberhart, R. (1995). Particle swarm optimization. IEEE International Conference on Neural Networks. Perth, 4, 1942-1948. https://doi.org/10.1109/ICNN.1995.488968
[23] Rothwell, R. (1994).Towards the fifthgeneration innovation process. International Marketing Review, 11(1), 7-31. https://doi.org/10.1108/02651339410057491

[24] Chen, M., Zhou, Y., Zhou, Y., Wang, Z., \& Jiang, P. (2014). A novel network performance evaluation method based on maximizing deviations. Telecommunication Systems, 55(1), 149-158. https://doi.org/10.1007/s11235-013-9759-1

[25] Abson, D. J., Dougill, A. J., \& Stringer, L. C. (2012). Using principal component analysis for information-rich socioecological vulnerability mapping in southern Africa. Applied Geography, 35(1-2), 515-524. https://doi.org/10.1016/j.apgeog.2012.08.004

[26] Mousavi-Nasab, S. H. \& Sotoudeh-Anvari, A. (2017). A comprehensive MCDM-based approach using TOPSIS, COPRAS and DEA as an auxiliary tool for material selection problems. Materials \& Design, 121, 237-253. https://doi.org/10.1016/j.matdes.2017.02.041

[27] Schutte, J. F. \& Groenwold, A. A. (2005). A study of global optimization using particle swarms. Journal of Global Optimization, 31(1), 93-108. https://doi.org/10.1007/s10898-003-6454-x

[28] Wang, Z. P. \& Tian, J. C. (2013). Research on optimal allocation of regional water resources based on particle swarm optimization. China Rural Water \& Hydropower, 1, 7-10.

[29] Blackwell, T. M. (2005). Particle swarms and population diversity. Soft Computing, 9(11), 793-802. https://doi.org/10.1007/s00500-004-0420-5

[30] Zhang L. P., Yu H. J., \& Hu S. X. (2005). Optimal choice of parameters for particle swarm optimization. Journal of Zhejiang University Science A, 6(6), 528-534. https://doi.org/10.1631/jzus.2005.A0528

\section{Contact information}

\section{Jingyu YIN, PhD}

(Corresponding author)

College of Economics and Management, Nanjing Forestry University,

No.159 Longpan Road, Nanjing,210037, Jiangsu China

E-mail: yinjingyu@hrbeu.edu.cn

Yi SU, Professor, PhD

(the second corresponding author)

School of Economics and Mangement, Harbin Engineering University, No.145, Nantong Road, Harbin 150000, China

E-mail: suyi@hrbeu.edu.cn 